\title{
Ploidy, expression of erbB1, erbB2, P53 and amplification of erbB1, erbB2 and erbB3 in non-small cell lung cancer
}

\author{
N. Reinmuth*, B. Brandt**, W-P. Kunze***, K. Junker ${ }^{+}$, M. Thomas ${ }^{++}$, \\ R. Achatzy***, H.H. Scheld*, M. Semik*
}

Ploidy, expression of $\operatorname{erb} B 1$, erbB2, P53 and amplification of $\operatorname{erb} B 1, \operatorname{erb} B 2$ and $\operatorname{erb} B 3$ in non-small cell lung cancer. N. Reinmuth, B. Brandt, W-P. Kunze, K. Junker, M. Thomas, $R$. Achatzy, H.H. Scheld, M. Semik. (C)ERS Journals Ltd 2000.

ABSTRACT: The aim of this study was to assess the prognostic value of deoxyribonucleic acid analysis, expression of erbB1, erbB2 and P53, and amplification levels of $e r b \mathrm{~B} 1, e r b \mathrm{~B} 2$ and $e r b \mathrm{~B} 3$ in non-small cell lung cancer (NSCLC).

Consecutive patients with NSCLC who underwent treatment with curative intention (118) were included. In 108 cases, the cell cycle was analysed using flow cytometry and double-staining with propidium iodide and anticytokeratin. In another 108 cases, expression of $e r b \mathrm{~B} 1$, erbB2 and P53 was assessed immunhistochemically. Amplification of the erbB family was determined in the tumours of 53 patients using doubledifferential polymerase chain reaction.

Of the tumours, $81 \%$ were aneuploid and $14 \%$ showed positive staining for $\operatorname{erbB} 1$, $18 \%$ for $e r b B 2$ and $41 \%$ for P53. There were normal mean gene copy numbers in $86 \%$ for $e r b \mathrm{~B} 1,94 \%$ for $e r b \mathrm{~B} 2$ and in $96 \%$ for $\operatorname{erbB} 3$. No significant correlations were noted between $\operatorname{erbB} 1, e r b \mathrm{~B} 2$ and $\mathrm{P} 53$ expression, ploidy status and tumour stage. In a Cox regression model, only tumour stage was shown to be prognostically significant.

It seems that ploidy and expression status of erbB1, erbB2 and P53 are not prognostic parameters in non-small cell lung cancer. Amplification of the erbB family does not seem to be a frequent event in non-small cell lung cancer.

Eur Respir J 2000; 16: 991-996.

\begin{abstract}
Depts of *Thoracic and Cardiovascular Surgery and ${ }^{++}$Haematology/Oncology and Respiratory Medicine, and **Institute of Clinical Chemistry and Laboratory Medicine, Westphalian Wilhelms-University, Muenster. ${ }^{* * *}$ Lung Clinic Hemer, Hemer, and Institute of Pathology, University Hospital Bergmannsheil, Bochum, Germany.
\end{abstract}

Correspondence: M. Semik, Dept of Thoracic and Cardiovascular Surgery, University Hospital, Westphalian Wilhelms-University, Albert-Schweitzer Str. 33, D-48129 Münster, Germany. Fax: 49 2518348316

Keywords: Amplification, erbB, nonsmall cell lung cancer, overexpression, ploidy, prognosis

Received: June 281999

Accepted after revision July 242000
Lung cancer is the leading cause of cancer death in the USA and Europe [1,2]. Non-small cell lung cancers (NSCLCs) are a biologically heterogeneous group of cancers with varying clinical presentations. Therefore, groups of patients with different prognosis need to be identified for treatment planning and outcome. The most accurate prognostic factor for patients with NSCLC is the tumour, node, metastasis (TNM) staging system, which is based on the anatomical extent of the tumour disease $[1$, 2]. However, even within the same TNM subset, there are obvious disparities in outcome. In patients with operable primary tumours, distant failure is a frequent event. Of patients thought to have stage I or II disease, disease will recur within 3 yrs after a curative operation in $\sim 40-50 \%$, which indicates that these patients cannot be cured by surgery alone [1]. Therefore, it appears that better techniques are needed for more accurate staging and identification of those patients at risk of disease relapse [3].

In recent years, several molecular markers have been detected in NSCLC [2, 4]. Malignancy results from deoxyribonucleic acid (DNA) damage, which modifies the normal checks and balances that regulate cellular proliferation and differentiation. Genetic alterations include the change of proto-oncogenes into oncogenes and the loss of tumour suppressor genes [5]. Conflicting information has been given regarding the relationship between overexpression of erbB1, erbB2, P53, ploidy, clinicopathological parameters and outcome $[2,6]$. Most published series have been retrospective studies that lacked accurate methods, analysed only one molecular marker and performed inappropriate analysis of laboratory results $[6,7]$. Furthermore, the molecular changes that lead to overexpression of the erbB family in NSCLC are not satisfactorily known. Therefore, a prospective study was conducted to investigate possible relations and the prognostic value of ploidy, expression of erbB1, $e r b \mathrm{~B} 2$ and $\mathrm{P} 53$, and amplification of erbB1, erbB2 and erbB3.

\section{Patients and methods}

\section{Patient selection}

Patients with primary NSCLC admitted between February 1993 and December 1994, who underwent surgical staging and R0 resection, were included in the study. An operation was considered to be R0 resection if the entire tumour was removed with microscopic negative surgical margins, an R1 resection if microscopic surgical margins were positive, and a $\mathrm{R} 2$ resection if gross tumour was left behind. Histological types of tumour were classified according to World Health Organization criteria [8]. The postsurgical stage of each tumour was determined according to the International Union Against Cancer [1]. Follow-up data were obtained at 1 and 2 yrs after 
treatment by the primary care physician. Patients who died from any cause, excluding lung cancer, were censored.

\section{Deoxyribonucleic analysis}

For each patient, a sample of the tumour was submitted for DNA quantification at the time of operation. The sample was either directly analysed or frozen at $-70^{\circ} \mathrm{C}$ for later analysis. Tumour cells were harvested using a scalpel, scraping along the fresh cut surface. The cells were suspended and fixed by the slow and dropwise addition of cold $\left(-20^{\circ} \mathrm{C}\right) 70 \%$ ethanol while agitating on a vortex mixer to give a final ethanol concentration of $50 \%$. After fixation and filtration through a nylon sieve (40 $\mathrm{mm}$ mesh width), the filtrate was washed in phosphate-buffered saline containing 5\% bovine serum/albumin (Behring, Marburg, Germany). The suspension was then diluted to $1 \times 10^{6}$ cells $\cdot \mathrm{mL}^{-1}$ and $20 \mu \mathrm{L}$ of this suspension was mixed with 20 $\mu \mathrm{g}$ fluorescein isothiocyanate labelled anticytokeratin (Dako MNF 116; Dako Hamburg, Germany). For DNA staining, the normal procedure of ribonuclease treatment (R4875; Sigma, Deisenhofen, Germany) and propidium iodide (Sigma; $50 \mu \mathrm{g} \cdot \mathrm{mL}^{-1}$ ) staining was performed. The intact anticytokeratin and propidium iodide dual-stained cell suspensions were analysed using a FACScan flow cytometer (Becton-Dickinson, San Jose, CA, USA) running Cell-fit software. The tumour samples were analysed at a low flow rate, with a mean measurement of 50,000 events per sample.

\section{Histogram analysis}

Keratin-positive cells were compared to keratinnegative cells as a diploid control. Every $\mathrm{G} 0 / \mathrm{G} 1$ peak consisting of $\geq 15 \%$ of all cells measured showing at least a discrete $\mathrm{G} 2 / \mathrm{M}$ peak was seen to represent a stem line of the tumour. The variation coefficient (CV) was assessed at every analysis. At the first ten flow cytometric analyses, the diploid control group was assumed to be represented by the first peak in the histogram without anticytokeratin staining because of an older software version.

Tumours were classified as aneuploid only if the tumour had more than one stem line or the $\mathrm{G} 0 / \mathrm{G} 1$ modal of the tumour was more than three-fold greater than the CV of the $\mathrm{G} 0 / \mathrm{G} 1$ modal of the control. The ploidy index was defined as the ratio of the carcinogenic $\mathrm{G} 0 / \mathrm{G} 1$ modal to the $\mathrm{G} 0 / \mathrm{G} 1$ modal of the control multiplied by two. In cases involving several stem lines, all calculations referred to the stem line containing the greatest number of tumour cells.

\section{Gene amplification analysis}

The gene dosages of erbB1, erbB2 and erbB3 were examined in frozen tumour tissue from 53 patients using double-differential polymerase chain reaction (PCR) (ddPCR) with leukocytes as negative control and superoxide dismutase 2 as the reference gene as described by BRANDT et al. [9]. The tumour samples were to be transported to the laboratory using isolated boxes transported containing dry ice and then stored again at $-70^{\circ} \mathrm{C}$ until analysis. The DNA was extracted using a nucleic acid extraction kit (Isoquick; Progen, Queensland,
Australia). The concentration and purity of the DNA was calculated by absorbance of ultraviolet light measurements. After adjustment for absorbance at $320 \mathrm{~nm}$, the ratio of the absorbance at 260 to $280 \mathrm{~nm}$ was used to determine DNA concentration.

\section{Protein expression analysis}

Immunohistochemical analysis was performed on representative paraffin blocks from each resected tumour. The staining procedure was as follows: 1) paraffin microtome sectioning (3-4 $\mu \mathrm{m})$ and slide labelling; 2) deparaffinization with xylol and ethanol; 3 ) antigen retrieval by heating four times in citrate buffer ( $\mathrm{pH} 6.0 ; 0.1 \mathrm{M})$ in a microwave for $5 \mathrm{~min}$ (full power; 1000 watts microwave) for P53 investigation or with heated target unmasking fluid (TUF) buffer $\left(95^{\circ} \mathrm{C}\right)$ (Dianova, Hamburg, Germany) for erbB1 and erbB2 assessment; 4) incubation with the (rabbit) polyclonal primary antibody (P53: CM-1 (Medac, Hamburg, Germany), erbB1: Ab-4 (Oncogene Science, Mineola, NY, USA), and erbB2: A0485 (Dako, Glostrup, Denmark)); 5) incubation with mouse antirabbit antibody and rabbit antimouse antibody; 6) development with alkaline phosphatase antialkaline phosphatase complex (Dako) and neu-fuchsin staining complex (Schmidt, Köngen, Germany); and 7) counterstaining with haematoxylin.

\section{Slide evaluation}

As negative control, the primary antibody was omitted. Sections from tumours with known erbB1, erbB2 or P53 overexpression served as positive control. ErbB1 and erbB2 slides were classified as positive if clear cytoplasmatic membrane staining of $\geq 5 \%$ of the malignant cells was observed. Clear nuclear staining of at $\geq 5 \%$ of the malignant cells was indicative of P53 accumulation. Minimal sporadic staining of an occasional isolated tumour cell and diffuse cytoplasmatic staining were interpreted as nonspecific.

\section{Statistics}

All patients and specimens received different codes which were revealed only during statistical analysis. The log rank test was used to compare the different subgroups with respect to cancer-specific survival. The Kaplan-Meier method was used to estimate the probability of survival as a function of time. The Cox proportional hazards modelling technique was used to identify which independent factor had a significant influence on overall survival.

\section{Results}

In 118 cases, NSCLC was histologically confirmed and the tumour completely resected with sufficient tumour-free periphery of the resection margin (table 1). Flow cytometric analysis was performed on 108 tumours. Eightyseven $(81 \%)$ tumours were aneuploid and $21(19 \%)$ diploid. The mean $\mathrm{CV}$ of the $\mathrm{G} 0 / \mathrm{G} 1$ peak of the diploid reference population was $6.48 \%$ (range $2.36-14.1 \%$ ). Fifty-nine $(55 \%)$ tumours had only one stem line, 48 
Table 1. - Clinical parameters of the 118 patients included in the study

\begin{tabular}{lc}
\hline Male/female & $108(92) / 10(8)$ \\
Age distribution yrs & \\
$<40$ & $1(1)$ \\
$40-49$ & $7(6)$ \\
$50-59$ & $38(32)$ \\
$60-69$ & $59(50)$ \\
$>69$ & $13(11)$ \\
Mean age yrs & 62 \\
Histology & \\
Squamous cell cancer & $48(41)$ \\
Adenocarcinoma & $31(26)$ \\
Undifferentiated large cell carcinoma & $39(33)$ \\
Tumour stage & \\
I & $76(64)$ \\
II & $9(8)$ \\
IIIA & $26(22)$ \\
IIIB & $5(4)$ \\
IV with ipsilateral lung metastases & $2(2)$ \\
Surgical treatment & \\
Lobectomy & $74(63)$ \\
Bilobectomy & $7(6)$ \\
Pneumectomy & $37(31)$ \\
Histological grade of differentiation & \\
1 & $6(5)$ \\
2 & $35(30)$ \\
3 & $74(63)$ \\
4 & $1(1)$ \\
Unknown & $2(2)$ \\
\hline
\end{tabular}

Data are presented as $\mathrm{n}(\%)$.

(44\%) had two and one (1\%) had three. Most tumours showed a DNA index of the first DNA peak of 1.8-2.2 (43 cases), illustrated in figure 1 . The distribution of stage, histology, tumour differentiation grade and age was not significantly different between the aneuploid and diploid groups.

In 108 tumours, expression of erbB1, erbB2 and P53 was assessed immunohistochemically. In one case, expression of P53 could not be determined because of insufficient quantity of tumour. No staining was observed in the surrounding non-neoplastic tissue. Fifteen (14\%) tumours were positive for erbB1, 19 (18\%) for erbB2 and 44 (41\%)

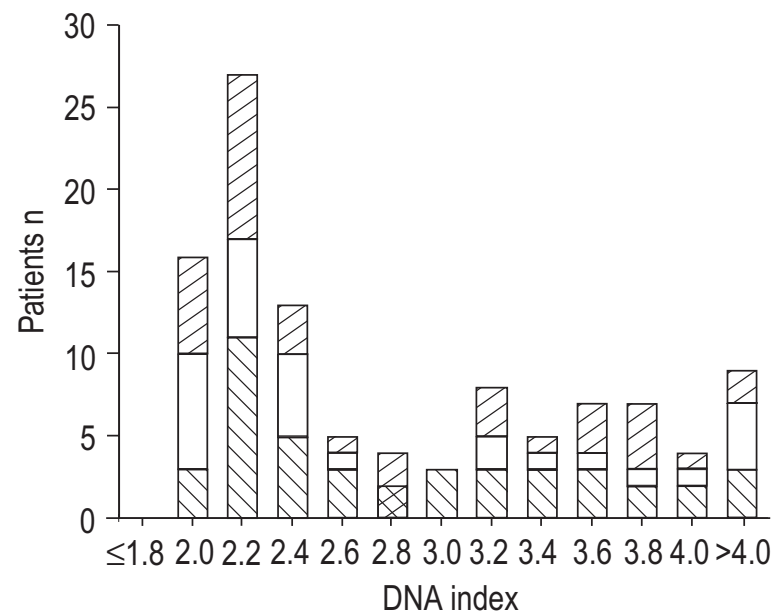

Fig. 1. - Distribution of deoxyribonucleic acid (DNA) indices $(n=108$; median 2.4 ; sD 0.79 ). $\mathbb{Z}$ : squamous cell cancer; $\square$ : adenocarcinoma; $\mathbb{\$}$ : large cell carcinoma.

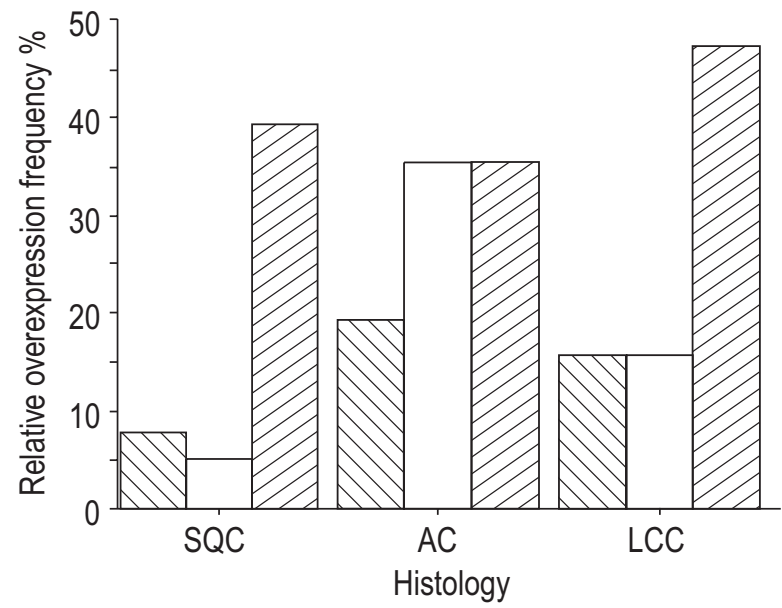

Fig. 2. - Relationship between expression of erbB1 ( $\mathbb{\nabla})$, erbB2 ( $\square$ ) and P53 $(\mathbb{Z})$ and histological type ( $\mathrm{n}=108 ; 107$ for P53). SQC: squamous cell cancer $(n=39 ; 38$ for P53); AC: adenocarcinoma $(n=31)$; LCC: large cell carcinoma $(\mathrm{n}=38)$.

for P53. Adenocarcinomas showed a significantly higher frequency of $e r b \mathrm{~B} 2$ overexpression (11 cases, 35\%) in comparison to other histological subgroups $(\mathrm{p}=0.004)$. No other significant differences of gene expression were seen with regards to tumour stage or histology (fig. 2). No significant correlations were noted between erbB1, erbB2 and P53 expression or ploidy status.

After extraction of DNA, 53 samples showed sufficient DNA concentration and purity (fig. 3). After ddPCR, the gene dosage of erbB1 could be evaluated in 37 tumours with acceptable results from the negative control, the reference gene and the tumour sample itself (fig. 4): for erbB1, normal mean gene copy numbers (AGCNs) were found in $32(86 \%)$ cases. Five tumours had an AGCNs of $>1.6$, i.e. three squamous cell carcinomas with AGCNs of $<2.0$ and two undifferentiated tumours with AGCNs of 2.4 and 4.3. All five tumours with AGCNs of $e r b \mathrm{~B} 1$ of $>1.6$ also showed overexpression. Fifty-two tumour samples were suitable for erbB2 analysis, of which 49

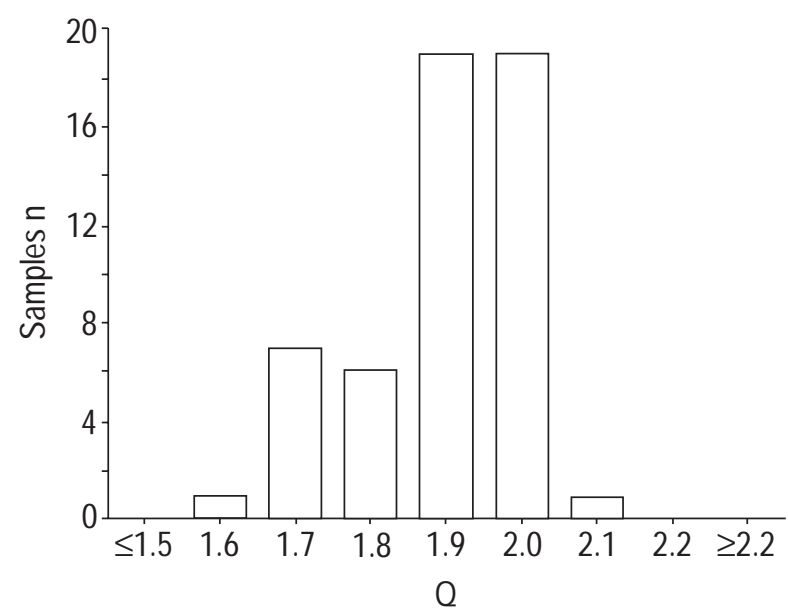

Fig. 3. - Degrees of purity of 53 tumour samples used for doubledifferential polymerase chain reaction after deoxyribonucleic acid isolation. Q: quotient of the corrected optical densities (ODs) measured photometrically at 260,280 and $320 \mathrm{~nm}\left(\mathrm{Q}=\left(\mathrm{OD}_{260-\mathrm{OD}} 20\right) /(\mathrm{OD} 280-\right.$ OD320). 


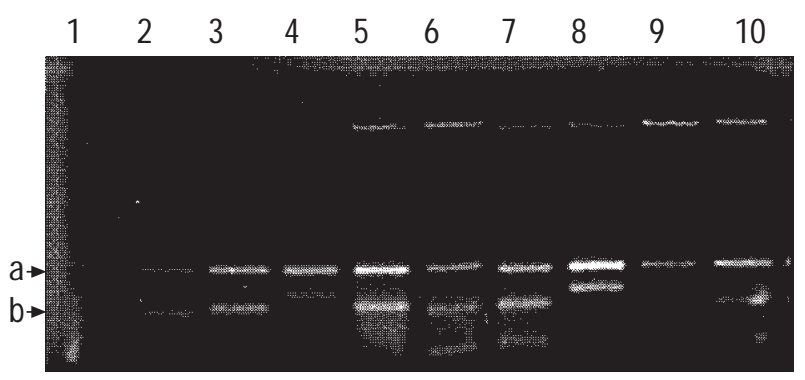

Fig. 4. - Electrophoretic analysis of the polymerase chain reaction (PCR) results obtained from three different non-small cell lung tumours. The degree of amplification was determined by comparison of the band intensity of the oncogene PCR product (b) with that of the reference gene band (a) in the ScanPack program (Biometra, Göttingen, Germany). Lanes 1-4; erbB1, erbB2, erbB3 and superoxide dismutase 2 (SOD2) (samples from tumour 1); lanes 5-8: erbB1, erbB2, erbB3 and SOD2 (tumour 2); lanes 9 and 10: erbB1 and erbB2 (tumour 3). No significant amplification could be detected. The density of the first lane could barely be assessed and was therefore excluded from further analysis.

tumours had normal AGCNs of erbB2. In addition, one adenocarcinoma had an AGCN of 2.0 and showed overexpression of erbB2. Two undifferentiated large cell cancers had AGCNs of 2.6 (without showing overexpression of erbB2) and 2.7. Expression of erbB2 in the latter tumour sample could not be determined because of repeated poor staining quality. Thus, interestingly, all tumours with more elevated erbB1 and erbB2 AGCNs were undifferentiated large cell carcinomas.

In 53 tumour samples, the AGCN of erbB3 could be determined. Thereby $51(96 \%)$ tumours had a normal AGCN. Two tumours had slightly elevated AGCNs, i.e. one adenocarcinoma and one undifferentiated tumour with AGCNs of 1.7 and 1.8 .

The mean follow-up was $\sim 2$ yrs (range $40-1,187$ days, one patient with postoperative death on day 40). Fourteen patients were excluded from further analysis: in six patients, histological examination of the resected tissue revealed R1 resection, five died because of insufficiency of the bronchial stump or pneumonia within 30 days postoperatively and three were lost to follow-up. The patients with $\mathrm{R} 1$ resection underwent adjuvant local radiation of the tumor site with 54 Gy. Performing the Cox regression test, patients with R1 resection had a significantly worse prognosis $(\mathrm{p}<0.0001)$.

Ninety-seven patients with analysis of the cell cycle and 100 patients with known levels of erbB1, erbB2 and P53 expression were suitable for survival analysis. Using Kaplan-Meier estimates for univariate analyses, neither ploidy status, ploidy index nor number of stem lines were statistically significant prognostic parameters. Likewise, expression of erbB1, erbB2 and P53 was of no prognostic value. When a Cox regression model was used to analyse sex, tumour stage, histology, operative procedure, expression of erbB1, erbB2 and P53, ploidy status and ploidy index, only the tumour stage was of prognostic value $(p=0.0206)$ for predicting both survival and the recurrencefree interval.

\section{Discussion}

In the present study, the prognostic value of ploidy status, expression of erbB1, erbB2 and P53, and gene dosage of erbB1, erbB2 and erbB3 were investigated prospectively. Patients with NSCLC (118) were included in the study. Patients with R1 resection followed by adjuvant radiation of the tumour site had a significantly worse prognosis $(p<0.0001)$, which is in accordance with other reports [10]. With a mean follow-up of $\sim 2$ yrs only tumour stage was shown to be prognostically significant. No prognostic value of sex, histology, ploidy status, ploidy index, or expression of erbB1, erbB2 or P53 was observed. Ploidy was independent of outcome, histology, stage, grade of differentiation, and expression of erbB1, erbB2 or P53.

The reported results concerning DNA analysis by flow cytometry are inconsistent. There are no specific guidelines concerning interpretation of the histograms. Different diploid reference populations, use of paraffin-embedded material and different classification of tumours as euploid or aneuploid prevent comparisons [11]. Stromal cells are seen as the optimal reference population [11]. By using anticytokeratin as a second stain for epithelial cells, the sensitivity of the interpretation of the histograms is markedly improved $[11,12]$. Most studies report an $80 \%$ prevalence of aneuploid tumours, which is in accordance with the present results $[13,14]$. Occurrence of aneuploidy seems to be independent of histology or grading or stage of tumour [14-16]. Several studies denied a prognostic value of ploidy $[14,16]$. MöRKVE et al. [16] analysed ploidy and the expression status of P53 in 112 NSCLCs using flow cytometry. As in the present study, ploidy was not correlated to expression of P53 or prognosis [16]. By using flow cytometry without second staining, differentiation between malignant and benign cells is not possible and staining artefacts cannot be excluded [11]. Therefore, their results concerning P53 expression cannot be compared with the present ones [16].

In contradistinction to breast cancer studies, there are only few studies concerning amplification of the erbB family in NSCLC $[17,18]$. Including the present series, it seems that amplification of the erbB family is a rise event in NSCLC and a rare reason for overexpression. Causes other than amplification are known to give rise to overexpression and may be the reason for these results [2]. SHIRAISHI et al. [17] reported on 10 NSCLCs with amplification of erbB1 of 114 tumours. Only one tumour of 51 investigated samples had an amplified erbB2 gene. SLebos et al. [18] failed to detect any amplification of $e r b \mathrm{~B} 1$ or erbB2 in 43 NSCLCs by Southern blot analysis.

A study performed by Gorgoulis et al. [19] examined the protein expression of paraffinized material from 40 squamous cell cancers immunohistochemically and investigated possible gene amplification using the semiquantitative differential PCR technique. Although over-expression was present in $65 \%$ for erbB $1,28 \%$ for $e r b \mathrm{~B} 2$ and $10 \%$ for erbB 3 , erbB 1 amplification was detected in only $11(28 \%)$ cases. There was only one tumour with amplified erbB2 and no tumours with amplification of erbB3 [19]. Similar to the present study, all tumours with erbB1 amplification showed overexpression. A tumour was defined as overexpressing a gene when either the cytoplasm or cell membranes were stained. There were no tumours showing overexpression of all investigated genes [19]. Because of consideration of the staining of both cytoplasm and cell membranes, the occurrence of overexpression may have been 
overestimated. Furthermore, any information about a necessary percentage of positive cells for classification as overexpressing a gene is missing [19].

The level of expression of $e r b \mathrm{~B} 1$ and $e r b \mathrm{~B} 2$ described in the literature varies considerably. The diversity of the results is influenced by various factors such as the ability of the antibody used to detect overexpression $[20,21]$ and the threshold value for assessment of positivity [20, 22, 23]. The threshold value for assessing positivity used by other groups has ranged from several positive cells to $>80 \%$ positive [20]. In the present study, only membrane staining was considered and a threshold value of 5\% used in order not to underestimate overexpression of erbB1. However, the clear majority of the present samples showed staining of markedly $>5 \%$ of the tumour cells.

In the present study, expression of erbB 1 and erbB2 was investigated immunohistochemically in 108 tumours in paraffin blocks. Although overexpression of erbB2 was found in $18 \%$ of the tumours, which is consistent with the results reported to data by other groups $[2,23]$, the results showed an occurrence of expression of erbB1 of $14 \%$. Adenocarcinomas showed significantly higher expression of $e r b \mathrm{~B} 2$. There were no significant correlations between tumour stage, expression of erbB1, erbB2 or $\mathrm{P} 53$, or ploidy status.

The lower frequency of erbB1 expression compared to the literature $[20,22,23]$ could have several explanations. It might be the result of more selective criteria of assessment of positivity (membrane staining only). However, it cannot be excluded that the sensitivity of detection of erbB1 expression may have been decreased by the fixation and paraffin embedding procedure [24].

PFEIFFER et al. [22] investigated the immunohistochemical expression of erbB1 and erbB2 in cryosections of 186 NSCLCs. Expression of erbB1 was higher in squamous cell carcinomas, whereas the level of erbB2 staining was higher in adenocarcinomas. Expression of either or both receptors was not correlated with prognosis [22].

Recently, PAStORINO et al. [23] published a retrospective study analysing the expression of erbB1, erbB2 and P53 in 515 cases of pathological stage I NSCLC immunohistochemically. None of these markers emerged as an independent predictive factor in survival.

P53 has been identified as a product of a tumour supressor gene which is frequently mutated in common human cancers including NSCLC [25]. Using a threshold value of $5 \%$ for the reasons indicated above, the prevalence of P53 overexpression was $41 \%$ in the present study, which is similar to the results of other studies [26, 27]. Several studies denied a prognostic value of P53 accumulation [4, 23, 25, 28, 29]. MCLAREN et al. [29] investigated 125 primary lung tumours using a panel of five anti-P53 antibodies and could not show any differences in survival between P53-positive and -negative cases. The polyclonal antibody CM-1, which was also used in the present study, produced quite intense staining compared to other markers [29]. These results indicate that, although P53 may be of considerable importance in the initiation of malignancy, it is probably of little prognostic significance once a tumour has developed [29].

The present data confirm the results of several previous studies that demonstrated no prognostic value of ploidy and expression of erbB1, erbB2 and P53. Amplification of the erbB family seems to be a rare event and not the cause of overexpression in most non-small cell lung cancers. In addition, P53 accumulation does not seem to be an indicator of worse prognosis. However, the purpose of using erbB1, erbB2 or P53 as targets in anticancer therapy needs to be determined [4]. Further studies are necessary to obtain a more precise idea of the molecular changes and pathobiological pathways that occur when lung cancer develops. Hopefully, with a better understanding of cancer genetics, new prognostic markers can be determined in order to better develop new therapeutic strategies.

\section{References}

1. Mountain CF. A new international staging system for lung cancer. Chest 1986; 89 (Suppl. 4): 225S-233S.

2. Fu X-L, Zhu X-Z, Shi D-R, et al. Study of prognostic predictors for non-small cell lung cancer. Lung Cancer 1999; 23: 143-152.

3. Kern JA, Slebos RJC, Top B, et al. c-erbB-2 expression and codon $12 \mathrm{~K}$-ras mutations both predict shortened survival for patients with pulmonary adenocarcinomas. $J$ Clin Invest 1994; 93: 516-520.

4. Carbone DP, Mitsudomi T, Chiba I, et al. p53 immunostaining positivity is associated with reduced survival and is imperfectly correlated with gene mutations in resected non-small cell lung cancer. Chest 1994; 106 (Suppl. 6): 377-381.

5. Hoffman B, Liebermann DA. Molecular controls of apoptosis: differentiation/growth arrest primary response genes, proto-oncogenes, and tumor suppressor genes as positive \& negative modulators. Oncogene 1994; 9: $1807-1812$.

6. Strauss GM, Kwiatkowski DJ, Harpole DH, Lynch T, Skarin A, Sugarbaker DJ. Molecular and pathologic markers in stage I non-small cell carcinoma of the lung. $J$ Clin Oncol 1995; 13: 1265-1279.

7. Levine MN, Browman GP, Gent M, Roberts R, Goodyear $\mathrm{M}$. When is a prognostic factor useful?: a guide for the perplexed. J Clin Oncol 1991; 9: 348-356.

8. World Health Organization. International Histological Classification of Tumours: Histological Typing of Lung Tumours. 2nd Edn. Geneva, World Health Organization, 1981.

9. Brandt B, Vogt U, Harms F, Bosse U, Zänker KS, Assmann G. Double-differential PCR for gene dosage estimation of erbB oncogenes in benign and cancer tissues and comparison to cellular DNA content. Gene 1995; 159: 29-34.

10. Snijder RJ, Brutel de la Rivière A, Elbers HJ, van den Bosch JM. Survival in resected stage I lung cancer with residual tumor at the bronchial resection margin. Ann Thorac Surg 1998; 65: 212-216.

11. Wersto RP, Liblit RL, Koss LG. Flow cytometric DNA analysis of human solid tumors: a review of the interpretation of DNA histograms. Human Pathol 1991; 22: 1085-1098.

12. van der Linden JC, Herman CJ, Boenders JGC, van de Sandt MM, Lindeman J. Flow cytometric DNA content of fresh tumor specimens using keratin-antibodies as second stain for two-parameters analysis. Cytometry 1992; 13: 163-168.

13. Ayabe H, Tomita M, Kawahara K, Tagawa Y, Tsuji H, Akamine S. DNA stemline heterogeneity of non-small cell lung carcinomas and differences in DNA ploidy between carcinomas and metastatic nodes. Lung Cancer 1994; 11: 201-208.

14. Rice TW, Bauer TW, Gephardt GN, Medendorp SV, 
McLain DA, Kirby TJ. Prognostic significance of flow cytometry in non-small-cell lung cancer. $J$ Thorac Cardiovasc Surg 1993; 106: 210-217.

15. Liewald F, Sunder-Plassmann L, Valet G, Wulf G, Weiss M, Schildberg FW. Durchflußcytometrische Analyse beim nicht-kleinzelligen Bronchialkarzinom und deren prognostische Bedeutung. Chirurg 1992; 63: 205-210.

16. Mörkve O, Halvorsen OJ, Skjaerven R, Gulsvik A, Laerum OD. Prognostic significance of p53 protein expression and DNA ploidy in surgically treated non-small cell lung carcinomas. Anticancer Res 1993; 13: 571-578.

17. Shiraishi M, Noguchi M, Shimosato Y, Sekiya T. Amplification of protooncogenes in surgical specimens of human lung carcinomas. Cancer Res 1989; 49: 64746479.

18. Slebos RJC, Evers SG, Wagenaar SS, Rodenhuis S. Cellular protooncogenes are infrequently amplified in untreated non-small cell lung cancer. Br J Cancer 1989; 59: $76-80$.

19. Gorgoulis V, Sfikakis PP, Karameris A, et al. Molecular and immunohistochemical study of class I growth factor receptor in squamous cell lung carcinomas. Pathol Res Pract 1995; 191: 973-981.

20. Busmanis I, Feleppa F, Jones A, et al. Analysis of cerbB2 expression using a panel of 6 commercially available antibodies. Pathology 1994; 26: 261-267.

21. Press MF, Hung G, Godolphin W, Slamon DJ. Sensitivity of HER-2/neu antibodies in archival tissue samples: potential source of error in immunohistochemical studies of oncogene expression. Cancer Res 1994; 54: 2771-2777.

22. Pfeiffer P, Clausen PP, Andersen K, Rose C. Lack of prognostic significance of epidermal growth factor receptor and the oncoprotein p185/HER-2 in patients with systemically untreated non-small-cell lung cancer: an immunhistochemical study on cryosections. Br J Cancer 1996; 74: 86-91.

23. Pastorino U, Andreola S, Tagliabue E, et al. Immunocytochemical markers in stage I lung cancer: relevance to prognosis. J Clin Oncol 1997; 15: 2858-2865.

24. Penault-Llorca F, Adelaide J, Houvenaeghel G, Hassoun J, Birnbaum D, Jacquemier J. Optimization of immunohistochemical detection of erbB2 in human breast cancer: impact of fixation. J Pathol 1994; 173: 65-75.

25. Fontanini G, Bigini D, Vignati S, et al. p53 expression in non small cell lung cancer: clinical and biological correlations. Anticancer Res 1993; 13: 737-742.

26. Guinee DG, Travis WD, Trivers GE, et al. Gender comparisons in human lung cancer: analysis of p53 mutations, anti-p53 serum antibodies and c-erbB-2 expression. Carcinogenesis 1995; 16: 993-1002.

27. Harpole DH, Herndon JE, Wolfe WG, Iglehart JD, Marks JR. A prognostic model of recurrence and death in stage I non-small cell lung cancer utilizing presentation, histopathology, and oncoprotein expression. Cancer Res 1995; 55: 51-56.

28. Passlick B, Izbicki JR, Häussinger K, Thetter O, Pantel K. Immunohistochemical detection of p53 protein is not associated with a poor prognosis in non-small-cell lung cancer. J Thorac Cardiovasc Surg 1995; 109: 1205-1211.

29. McLaren R, Kuzu I, Dunnill M, Harris A, Lane D, Gater KC. The relationship of $\mathrm{p} 53$ immunostaining to survival in carcinoma of the lung. Br J Cancer 1992; 66: 735-738. 